\title{
The functional role of dendritic cells in atherogenesis (Review)
}

\author{
PAOLO PUDDU, GIOVANNI M. PUDDU, ELEONORA CRAVERO, SILVIA MUSCARI and ANTONIO MUSCARI
}

\author{
Department of Internal Medicine, Aging and Nephrological Diseases, \\ University of Bologna and S. Orsola-Malpighi Hospital, 40138 Bologna, Italy
}

Received January 26, 2010; Accepted April 28, 2010

DOI: $10.3892 / \mathrm{mmr} \_00000295$

\begin{abstract}
Accumulating evidence suggests that dendritic cells (DCs) play a crucial role in the generation and progression of atherosclerosis (ATS), a lipid-related immuno-inflammatory disease. DCs have the ability to process and present antigens (mainly oxidized low-density lipoproteins, heat shock proteins and fragments of necrotic or apoptotic cells) to naïve $\mathrm{T}$ cells, and the activation of $\mathrm{T}$ cells is a key step for the progression of atherosclerotic disease. The existence of some distinct DC subtypes has now become evident. The main categories of DC subsets are the 'conventional or myeloid' and the 'plasmacytoid', which differ in toll-like receptor type and site of expression, pathogens and antigens recognized, and effector cytokines and functions. Studies on the potential impact of DCs in the pathogenesis of ATS may lead to novel therapies to regulate the immunoreactions occurring in atherogenesis. In particular, diltiazem, peroxisome proliferator activated receptor agonists and statins have been shown to protect endothelial cell function by inhibiting DCs, a mechanism that may play a significant role in the prevention of ATS.
\end{abstract}

\section{Contents}

1. Introduction

2. Dendritic cells: origin and functions

3. Dendritic cells and atherogenesis

4. Dendritic cells as possible targets in the treatment of atherosclerosis

5. Conclusions

\section{Introduction}

It is now well accepted that atherosclerosis (ATS) is a chronic disease of the arterial wall involving both innate and adaptive

Correspondence to: Dr Antonio Muscari, Department of Internal Medicine, Aging and Nephrological Diseases, University of Bologna and S. Orsola-Malpighi Hospital, Via Albertoni 15, 40138 Bologna, Italy

E-mail: antonio.muscari@unibo.it

Key words: dendritic cells, atherosclerosis immuno-inflammatory mechanisms (1-3). In fact, endogenously modified molecules such as oxidized and glycated lipoproteins are known to stimulate the inflammatory and immune responses that promote ATS development, progression and complications $(1,4)$. The main cellular components of atherosclerotic lesions are macrophages, $\mathrm{T}$ cells and smooth muscle cells (SMCs) (5-7). Previous studies have also reported the presence of dendritic cells (DCs) in plaques (8-11). DCs are considered powerful components of the immune system with a markedly elevated capacity to stimulate $\mathrm{T}$ and $\mathrm{B}$ cells and to control the differentiation of T cells (12).

Experimental and clinical studies have suggested that DCs may be involved in atherogenesis (13). This review summarizes the main recent advances in determining the functional role of DCs in the development, progression and complications of ATS.

\section{Dendritic cells: origin and functions}

DCs are a heterogeneous population of bone marrow-derived immune cells that specialize in capturing, processing and presenting antigens to $\mathrm{T}$ lymphocytes in order to induce and control immunity (14). DCs are morphologically characterized by the presence of several thin cytoplasmic processes (dendrites) and by large cytoplasmic veils that are continuously extended and retracted (15). DCs are very efficient at internalizing antigens either by phagocytosis or by receptormediated endocytosis, subsequently displaying a fragment of the antigen, bound to a class II major histocompatibility complex (MHC), on their membrane. T cells recognize the antigen-class II MHC molecule complex and interact with it on the DC membrane. An additional co-stimulatory signal is then produced by the DCs, such as B7-1, B7-2, leading to the activation of T cells.

It is now widely accepted that DCs are a part of the mononuclear phagocytic system, and comprise several subpopulations of migratory and lymphoid organ resident types derived from a common $\mathrm{CD} 34^{+}$precursor $(12,16)$. From the bone marrow, DC progenitors migrate through the bloodstream to reach sites of potential antigen entry, particularly along epithelial and body cavity surfaces $(12,15,17,18)$. From these sites, 'immature' or 'processing' DCs migrate into lymphoid tissues to complete their maturation. However, some of them also maturate in the non-lymphoid peripheral tissues and present antigenic proteins to circulatory $\mathrm{T}$ cells. The maturation process of DCs is known to be modulated by 
Table I. Characterization of conventional myeloid and plasmacytoid dendritic cells (DCs).

\begin{tabular}{lll}
\hline Feature & \multicolumn{1}{c}{ Conventional myeloid DCs } & \multicolumn{1}{c}{ Plasmacytoid DCs } \\
\hline Preferential TLR expression & TLR2, TLR4 & TLR7, TLR8, TLR9 \\
Site of TLR expression & Cell surface & Cytoplasm \\
Pathogens recognized & Bacterial fragments & Viral DNA and RNA \\
Autoantigens recognized & Oxidized LDL, heat shock protein 60 & Nucleotides from dying cells \\
Effector function & Activation of T cells & TRAIL up-regulation on cytotoxic T cells in the plaque \\
Effector cytokines & TNF $\alpha$, IL-6, IL-12 & Type I interferon
\end{tabular}

IL, interleukin; TLR, toll-like receptor; TNF, tumor necrosis factor; TRAIL, TNF-related apoptosis-inducing ligand. Modified from Niessner and Weyand (23).

varying combinations of cytokine growth factors, including tumor necrosis factor (TNF)- $\alpha$, granulocyte macrophage colony stimulating factor (GM-CSF), interleukin (IL)-4, stem cell factors, transforming growth factor $\beta$ and flt-3 ligands $(12,15,17,18)$. The precise nature of the DC precursor that migrates from the bone marrow via the blood stream to the target tissues is not yet known. Furthermore, it remains to be fully elucidated at which stage the DC lineage diverges from that of monocytes (19).

The existence of many distinct DC subtypes has now become evident. They differ in surface markers, migratory patterns, localization and dependence on various infectious and inflammatory stimuli for their generation (20-22). The main categories of DC subsets are 'conventional or myeloid' (cDCs) and the 'plasmacytoid' (pDCs). Table I summarizes the functional properties of cDCs and pDCs (23).

cDCs are further divided into distinct subcategories on the basis of their origin, location and different expression of surface markers (24). These categories comprise the Langherans cells and dermal cells present in the skin, as well as various subsets of epithelial DCs, including pulmonary DCs (25).

pDCs are preferentially located in the shoulder region of the ATS plaque and have the ability to secrete large amounts of type I interferon (IFN-I). The IFN-I $\alpha$ produced by pDCs is capable of inducing marked up-regulation of the TRAIL molecule (TNF-related apoptosis-inducing ligand) in CD4 T cells (26). T cell-mediated apoptosis of plaque-residing cells, such as endothelial cells (ECs) and VSMCs, is considered an important mechanism in plaque destabilization and rupture (26,27).

Recent research readdressing the role of each subset in antigen presentation 'in vivo' has focused on the complexity of the DC network (25). The unique ability of DCs to activate 'naïve' $\mathrm{T}$ cells is dependent on their stage of maturation and on their capacity to express high levels of class I and II MHC molecules, human leukocyte antigen-DR, and CDIa and its co-stimulatory molecules, CD40 and CD80/CD86.

CD40 is a member of the TNF superfamily, which is activated by the CD40 ligand (CD40L). CD40-CD40L are present in human ATS lesions and are expressed by macrophages, SMCs and T cells. CD40-CD40L signaling induces the release of cytokines and the expression of chemokines. It has been shown that DCs, upon constant CD40L stimulation, provide long-lasting IL-12 responses (28-30). For T cell activation, co-stimulation by the ligands CD80/CD86 and their CD28 receptor on $\mathrm{T}$ cells are also required $(9,12,31,32)$.

In conclusion, upon migration and maturation, DCs develop not only the ability to capture and process antigens, but also the necessary molecules to engage lymphocytes and initiate immune programs. DCs may therefore be regarded as the 'sentinels' that orchestrate the immune system (24).

\section{Dendritic cells and atherogenesis}

DCs are present in healthy arteries and have been documented in the subendothelial space and at the mediaadventitia junction $(33,34)$. The localization of DCs adjacent to the vasa vasorum allows them to monitor the most important access pathways to the vessel wall, to present autoantigens to T cells, and to locally initiate inflammatory responses (23). Of the modified self-antigens expressed in ATS plaques, the best characterized is oxidized LDL. Stress-induced heat shock proteins represent a second category of autoantigens, while a third category consists of dying cells in both apoptotic and necrotic processes.

Inflammatory DCs (e.g., TNF or iNOS producing DCs) $(22,35)$ are not present in the steady state. Weber et al (4) suggested that inflammatory DCs may differentiate from the Ly6 $\mathrm{C}^{\text {low }}$ monocyte and promote ATS lesions. However, further investigation is required to clarify both the development of DC precursors into each subpopulation and the classification of DC subgroups regarding ATS disease (36).

It has been demonstrated that DCs accumulate in the arterial intima in the regions that are subjected to major haemodynamic stress by turbulent flow conditions, which results in a predisposition to the development of ATS (37). DCs have been identified in atherosclerotic plaques, where they co-localize with $\mathrm{T}$ cells and are located in the neovascularization areas associated with inflammatory substrates.

The relationship between DCs and ATS has been assessed by several studies under experimental conditions and in humans. Studies on diet-induced hypercholesterolaemia demonstrated the presence of DCs in the aortic ATS lesions of apoE-deficient mice (11). In rats, DCs were also found during arterial neo-intima formation after balloon injury (38). DCs are present in human unstable ATS plaques $(26,39)$, and higher DC densities were found in carotid plaques from symptomatic 
patients as compared to those from asymptomatic patients (40). DCs were also described in human symptomatic in-stent restenosis (41) and in aortic aneurysms (42).

A decrease in circulating DCs appears to be an independent predictor of the presence of coronary artery disease (43). The levels of circulating DC precursors were reduced in both acute and chronic coronary syndromes as compared to healthy controls, probably due to vascular recruitment. Moreover, the number of circulating DCs was inversely correlated with C-reactive protein and IL-6.

On the other hand, Gautier et al (44) found that the expansion of the DC population was not associated with an acceleration of ATS plaque progression in either LDL receptor-deficient or apoE-deficient mice. In these experimental situations, the expansion of the DC population was associated with an atheroprotective decrease in plasma cholesterol levels. These data suggest that DCs may be key players in ATS through their impact on not only the immune response, but also on cholesterol homeostasis regulation.

Overall, these studies support the hypothesis that DCs may be strongly involved in ATS generation and progression. However, the modulation of immune processes, which is maintained by the heterogeneous population of DCs with specialized function, requires further investigation. In particular, understanding the mechanisms involved in the homeostasis of DC subsets in steady state and inflammatory conditions is key to exploiting their therapeutic potential (45).

\section{Dendritic cells as possible targets in the treatment of atherosclerosis}

The novel in vivo evidence that DCs broadly impact the circulating levels of cholesterol and immune responses in ATS opens new therapeutic horizons in the treatment of ATS (44).

Bachetoni et al (46) showed that diltiazem impairs the maturation and function of DCs, with subsequent inhibition of $\mathrm{T}$ cell activation and possible prevention of ATS.

In 2004, Luo et al (47) suggested that the peroxisome proliferator activated receptor (PPAR) $-\gamma$ agonist ciglitazone inhibited the ox-LDL-induced maturation and immune functions of DCs. More recently, Shi et al (48) observed that the PPAR- $\alpha$ agonist fenofibrate, which has favorable effects on the development of ATS, also inhibited the ox-LDL-induced immune maturation of DCs. These effects of PPARs may partially explain their ability to slow ATS progression and reduce the risk of coronary heart disease independently from their metabolic effects.

Statins, the inhibitors of 3-hydroxy-3-methylglutaryl-CoA reductase, are widely used as cholesterol-lowering agents, but have also been shown to possess immunomodulatory properties (49-51). Recently, Yilmaz et al (52) showed that pre-incubation with statins of lipolysaccharide-stimulated DCs significantly suppressed their endocytosis, basal secretion of proinflammatory cytokines and ability to induce $\mathrm{T}$ cell proliferation and activation. Furthermore, Kofler et al (53) investigated the role of statins in regulating $\mathrm{DC} / \mathrm{EC}$ interactions. The exposure of human DCs to low-moderate atorvastatin concentrations decreased their invasion capability (adhesion/transmigration), probably through changes in cholesterol biosynthesis within DC membrane domains $(54,55)$ and by the inhibition of protein geranyl-geranylation. Kajimoto et al (56) provided the first clinical evidence that statins (atorvastatin) at $20 \mathrm{mg}$ / day for 4 weeks significantly reduce DCs, key inflammatory factors (including c-Jun IV-terminal kinase) and matrix metalloproteinase expression in the aortic wall of patients undergoing abdominal aorta replacement. These results partially contribute to the explanation of the beneficial effects of statins in the treatment of ATS.

\section{Conclusions}

Accumulating evidence suggests that DCs may play a key role in atherogenesis, as they are the most potent antigen-presenting cells and participate in the enhancement and regulation of cell-mediated immune reactions. Endothelial activation and injury by exposure to ox-LDL, TNF $\alpha$, hypoxia and infection favour DC adhesion and transmigration. The maturation of DCs boosts their ability to present antigens to naïve cells. DC-induced $\mathrm{T}$ cell activation appears to be crucial in both the generation and progression of ATS, a chronic lipid-related immuno-inflammatory disease.

The experimental data on the potential impact of DCs in the pathogenesis of ATS may lead to new therapeutic strategies for regulating immunoreactions in atherogenesis. The atheroprotective effects of statins and PPAR agonists may be due, in part, to their ability to interfere with DC function and EC/DC interactions. However, further investigations and clinical trials are required to elucidate the possible use of DC-targeting drugs in the treatment of atherosclerotic disease.

\section{References}

1. Tedgui A and Mallat Z: Cytokines in atherosclerosis: pathogenic and regulatory pathways. Physiol Rev 86: 515-581, 2006.

2. Jawień J: New insights into immunological aspects of atherosclerosis. Pol Arch Med Wewn 118: 127-131, 2008.

3. Hansson GK: Atherosclerosis - an immune disease: the Anitschkov lecture 2007. Atherosclerosis 202: 2-10, 2009.

4. Weber C, Zernecke A and Libby P: The multifaceted contributions of leukocyte subsets to atherosclerosis: lessons from mouse models. Nat Rev Immunol 8: 802-815, 2008.

5. Hansson GK: Immune mechanisms in atherosclerosis. Arterioscler Thromb Vasc Biol 21: 1876-1890, 2001.

6. Gown AM, Tsukada T and Ross R: Human atherosclerosis. II. Immunocytochemical analysis of the cellular composition of human atherosclerotic lesions. Am J Pathol 125: 191-207, 1986.

7. Hansson GK, Holm $J$ and Jonasson L: Detection of activated $T$ lymphocytes in the human atherosclerotic plaque. Am J Pathol 135: 169-175, 1989.

8. Link A and Böhm M: Potential role of dendritic cells in atherogenesis. Cardiovasc Res 55: 708-709, 2002.

9. Bobryshev YV and Lord RS: Mapping of vascular dendritic cells in atherosclerotic arteries suggests their involvement in local immune-inflammatory reactions. Cardiovasc Res 37: 799-810, 1998.

10. Ozmen J, Bobryshev YV, Lord RS and Ashwell KW: Identification of dendritic cells in aortic atherosclerotic lesions in rats with diet-induced hypercholesterolaemia. Histol Histopathol 17: 223-237, 2002.

11. Bobryshev YV, Taksir T, Lord RS and Freeman MW: Evidence that dendritic cells infiltrate atherosclerotic lesions in apolipoprotein E-deficient mice. Histol Histopathol 16: 801-808, 2001.

12. Banchereau J and Steinman RM: Dendritic cells and the control of immunity. Nature 392: 245-252, 1998.

13. Sharma R and Li DZ: Role of dendritic cells in atherosclerosis. Asian Cardiovasc Thorac Ann 14: 166-169, 2006.

14. Mallat Z, Taleb S, Ait-Oufella $\mathrm{H}$ and Tedgui A: The role of adaptive $\mathrm{T}$ cell immunity in atherosclerosis. J Lipid Res 50: S364-S369, 2009. 
15. Lotze MT and Thomson AW (eds): Dendritic Cells: Biology and Clinical Applications. 2nd edition. Academic Press, San Diego, CA, 2001.

16. Hume DA: Macrophages as APC and the dendritic cell myth. J Immunol 181: 5829-5835, 2008.

17. Lipscomb MF and Masten BJ: Dendritic cells: immune regulators in health and disease. Physiol Rev 82: 97-130, 2002.

18. Steinman RM, Hawiger D and Nussenzweig MC: Tolerogenic dendritic cells. Annu Rev Immunol 21: 685-711, 2003.

19. Liu K, Victora GD, Schwickert TA, Guermonprez $P$ Meredith MM, Yao K, Chu FF, Randolph GJ, Rudensky AY and Nussenzweig M: In vivo analysis of dendritic cell development and homeostasis. Science 324: 392-397, 2009.

20. Conti L, Cardone M, Varano B, Puddu P, Belardelli $F$ and Gessani S: Role of the cytokine environment and cytokine receptor expression on the generation of functionally distinct dendritic cells from human monocytes. Eur J Immunol 38 750-762, 2008

21. Conti L and Gessani S: GM-CSF in the generation of dendritic cells from human blood monocyte precursors: recent advances. Immunobiology 213: 859-870, 2008.

22. Shortman K and Naik SH: Steady-state and inflammatory dendritic-cell development. Nat Rev Immunol 7: 19-30, 2007.

23. Niessner A and Weyand CM: Dendritic cells in atherosclerotic disease. Clin Immunol 134: 25-32, 2009.

24. Buckwalter MR and Albert ML: Orchestration of the immune response by dendritic cells. Curr Biol 19: R355-R361, 2009.

25. Segura E and Villadangos JA: Antigen presentation by dendritic cells in vivo. Curr Opin Immunol 21: 105-110, 2009.

26. Niessner A, Sato K, Chaikof EL, Colmegna I, Goronzy JJ and Weyand CM: Pathogen-sensing plasmacytoid dendritic cells stimulate cytotoxic T-cell function in the atherosclerotic plaque through interferon-alpha. Circulation 114: 2482-2489, 2006.

27. Niessner A, Shin MS, Pryshchep O, Goronzy JJ, Chaikof EL and Weyand CM: Synergistic proinflammatory effects of the antiviral cytokine interferon-alpha and Toll-like receptor 4 ligands in the atherosclerotic plaque. Circulation 116: 2043-2052, 2007.

28. Loskog A, Ninalga $\mathrm{C}$ and Tötterman TH: Dendritic cells engineered to express CD40L continuously produce IL12 and resist negative signals from $\operatorname{Tr} 1 / \mathrm{Th} 3$ dominated tumors. Cancer Immunol Immunother 55: 588-597, 2006.

29. Kobayashi T, Walsh MC and Choi Y: The role of TRAF6 in signal transduction and the immune response. Microbes Infect 6: 1333-1338, 2004

30. Lievens D, Eijgelaar WJ, Biessen EA, Daemen MJ and Lutgens E: The multi-functionality of CD40L and its receptor CD40 in atherosclerosis. Thromb Haemost 102: 206-214, 2009.

31. Beckman EM and Brenner MB: MHC class I-like, class II-like and CD1 molecules: distinct roles in immunity. Immunol Today 16: 349-352, 1995.

32. Carreno BM and Collins M: The B7 family of ligands and its receptors: new pathways for costimulation and inhibition of immune responses. Annu Rev Immunol 20: 29-53, 2002.

33. Ma-Krupa W, Jeon MS, Spoerl S, Tedder TF, Goronzy JJ and Weyand CM: Activation of arterial wall dendritic cells and breakdown of self-tolerance in giant cell arteritis. J Exp Med 199: 173-183, 2004

34. Pryshchep O, Ma-Krupa W, Younge BR, Goronzy JJ and Weyand CM: Vessel-specific Toll-like receptor profiles in human medium and large arteries. Circulation 118: 1276-1284, 2008.

35. Randolph GJ, Ochando J and Partida-Sánchez S: Migration of dendritic cell subsets and their precursors. Annu Rev Immunol 26: 293-316, 2008

36. Shimada K: Immune system and atherosclerotic disease: heterogeneity of leukocyte subsets participating in the pathogenesis of atherosclerosis. Circ J 73: 994-1001, 2009.

37. Millonig G, Niederegger H, Rabl W, Hochleitner BW, Hoefer D, Romani N and Wick G: Network of vascular-associated dendritic cells in intima of healthy young individuals. Arterioscler Thromb Vasc Biol 21: 503-508, 2001

38. Bauriedel G, Jabs A, Skowasch D, Hutter R, Badimon JJ, Fuster V, Welsch U and Lüderitz B: Dendritic cells in neointima formation after rat carotid balloon injury: coordinated expression withanti-apoptotic Bcl-2 and HSP47 in arterial repair. J Am Coll Cardiol 42: 930-938, 2003.
39. Yilmaz A, Lochno M, Traeg F, Cicha I, Reiss C, Stumpf C, Raaz D, Anger T, Amann K, Probst T, Ludwig J, Daniel WG and Garlichs CD: Emergence of dendritic cells in rupture-prone regions of vulnerable carotid plaques. Atherosclerosis 176 101-110, 2004.

40. Kawahara I, Kitagawa N, Tsutsumi K, Nagata I, Hayashi T and Koji T: The expression of vascular dendritic cells in human atherosclerotic carotid plaques. Hum Pathol 38: 1378-1385, 2007.

41. Skowasch D, Jabs A, Andrié R, Dinkelbach S, Lüderitz B and Bauriedel G: Presence of bone-marrow- and neural-crest-derived cells in intimal hyperplasia at the time of clinical in-stent restenosis. Cardiovasc Res 60: 684-691, 2003.

42. Bobryshev YV, Lord RS and Pärsson H: Immunophenotypic analysis of the aortic aneurysm wall suggests that vascular dendritic cells are involved in immune responses. Cardiovasc Surg 6: 240-249, 1998

43. Yilmaz A, Schaller T, Cicha I, Altendorf R, Stumpf C Klinghammer L, Ludwig J, Daniel WG and Garlichs CD: Predictive value of the decrease in circulating dendritic cell precursors in stable coronary artery disease. Clin Sci 116 353-363, 2009.

44. Gautier EL, Huby T, Saint-Charles F, Ouzilleau B, Pirault J, Deswaerte V, Ginhoux F, Miller ER, Witztum JL, Chapman MJ and Lesnik P: Conventional dendritic cells at the crossroads between immunity and cholesterol homeostasis in atherosclerosis. Circulation 119: 2367-2375, 2009.

45. Merad M and Manz MG: Dendritic cell homeostasis. Blood 113: 3418-3427, 2009.

46. Bachetoni A, D'Ambrosio A, Mariani P, Cortesini R and Quintieri F: Diltiazem impairs maturation and functions of human dendritic cells. Hum Immunol 63: 524-533, 2002.

47. Luo Y, Liang C, Xu C, Jia Q, Huang D, Chen L, Wang K, Wu Z and Ge J: Ciglitazone inhibits oxidized-low density lipoprotein induced immune maturation of dendritic cells. J Cardiovasc Pharmacol 44: 381-385, 2004.

48. Shi HY, Ge JB, Fang WY, Yao K, Sun AJ, Huang RC, Jia QZ, Wang KQ, Zou YZ and Cao XT: Peroxisome proliferatoractivated receptor alpha agonist attenuates oxidized-low density lipoprotein induced immune maturation of human monocytederived dendritic cells. Chin Med J 121: 1747-1750, 2008.

49. Kwak B, Mulhaupt F, Myit S and Mach F: Statins as a newly recognized type of immunomodulator. Nat Med 6: 1399-1402, 2000.

50. Aktas O, Waiczies S, Smorodchenko A, Dorr J, Seeger B, Prozorovski T, Sallach S, Endres M, Brocke S, Nitsch R and Zipp F: Treatment of relapsing paralysis in experimental encephalomyelitis by targeting Th1 cells through atorvastatin. J Exp Med 197: 725-733, 2003.

51. Youssef S, Stüve O, Patarroyo JC, Ruiz PJ, Radosevich JL, Hur EM, Bravo M, Mitchell DJ, Sobel RA, Steinman L and Zamvil SS: The HMG-CoA reductase inhibitor, atorvastatin, promotes a Th2 bias and reverses paralysis in central nervous system autoimmune disease. Nature 420: 78-84, 2002.

52. Yilmaz A, Reiss C, Weng A, Cicha I, Stumpf C, Steinkasserer A, Daniel WG and Garlichs CD: Differential effects of statins on relevant functions of human monocyte-derived dendritic cells. J Leukoc Biol 79: 529-538, 2006.

53. Kofler S, Schlichting C, Jankl S, Nickel T and Weis M: Dual mode of HMG-CoA reductase inhibition on dendritic cell invasion. Atherosclerosis 197: 105-110, 2008.

54. Skaletz-Rorowski A, Lutchman M, Kureishi Y, Lefer DJ, Faust JR and Walsh K: HMG-CoA reductase inhibitors promote cholesterol-dependent Akt/PKB translocation to membrane domains in endothelial cells. Cardiovasc Res 57: 253-264, 2003.

55. Harris MB, Blackstone MA, Sood SG, Li C, Goolsby JM, Venema VJ, Kemp BE and Venema RC: Acute activation and phosphorylation of endothelial nitric oxide synthase by HMG-CoA reductase inhibitors. Am J Physiol Heart Circ Physiol 287: H560-H566, 2004

56. Kajimoto K, Miyauchi K, Kasai T, Shimada K, Kojima Y, Shimada A, Niinami H, Amano A and Daida H: Short-term 20-mg atorvastatin therapy reduces key inflammatory factors including c-Jun $\mathrm{N}$-terminal kinase and dendritic cells and matrix metalloproteinase expression in human abdominal aortic aneurysmal wall. Atherosclerosis 206: 505-511, 2009. 